\title{
The frequency of parent-reported motor coordination difficulties in children diagnosed with benign joint hypermobility syndrome
}

\author{
C Bernie*, SM Maillard \\ From 18th Pediatric Rheumatology European Society (PReS) Congress \\ Bruges, Belgium. 14-18 September 2011
}

\section{Background}

In recent studies, joint hypermobility in childhood has been associated with poorer activity participation and quality of life outcomes. In addition, evidence suggests that these children are more likely to present with motor co-ordination difficulties. Reduced motor competence in childhood has a range of reported long term adverse health outcomes including obesity, decreased self esteem, and secondary mental health issues such as anxiety and depression. This group therefore warrants further study, along with appropriate and timely interventions.

\section{Aims}

To investigate the reported frequency and functional impact of motor-based difficulties in children presenting to a tertiary assessment clinic for biomechanical pain related to joint hypermobility.

\section{Methods}

Data was collected from children and primary caregivers who attended a tertiary multidisciplinary assessment clinic between 2005 and 2009. Measures included recorded interview responses, range-of-motion testing, and functional assessment tools such as the Childhood Health Assessment Questionnaire (CHAQ). Data was collated and analyses completed using Welch's T-tests for significance.

\section{Results}

Out of 200 children assessed (40\% male, age range 5-16 years), 172 children met criteria for Benign Joint
Hypermobility Syndrome (BJHS). Of these, clumsiness was reported in $50.6 \%, 46.5 \%$ reported coordination difficulties, and $34.9 \%$ identified poor ball skills. In addition, $22.7 \%$ reported all three issues, indicating that almost a quarter of this group present with widespread motor-based deficits. This is considerably higher than recent published estimates for the United Kingdom, reporting that $4 \%$ of children have moderate coordination difficulties. Children with BJHS and reported coordination difficulties also presented with higher CHAQ scores $(\mathrm{p}<.001)$ than other study participants.

\section{Conclusions}

Children presenting with joint hypermobility frequently report motor coordination dysfunction. Within the BJHS group, children with reported coordination issues present with greater impairment in activities of daily living. Services should support such children to improve participation, independence, and quality of life, whilst aiming to prevent the onset of secondary health problems.

Published: 14 September 2011

doi:10.1186/1546-0096-9-S1-035

Cite this article as: Bernie and Maillard: The frequency of parentreported motor coordination difficulties in children diagnosed with benign joint hypermobility syndrome. Pediatric Rheumatology 20119 (Suppl 1):035.

* Correspondence: Bernic@gosh.nhs.uk

Rheumatology Department, Great Ormond Street Hospital, London, UK

(c) 2011 Bernie and Maillard; licensee BioMed Central Ltd. This is an open access article distributed under the terms of the Creative 